their data cannot be immediately compared with ours. However, they report concentrations between 6.5 and $87 \%$ vol at a depth of $80 \mathrm{~cm}$ and a flux ranging between 0.23 and $2.641 \mathrm{~m}^{-2} \mathrm{~h}^{-1}$. Assuming that $\mathrm{CO}_{2}$ flux is exclusively supported by diffusion, that the concentration gradient is constant, that the diffusion coefficient is $0.12 \mathrm{~cm}^{2} \mathrm{~s}^{-1}$, and that soil porosity is 0.33 (ref. 3 ), specific $\mathrm{CO}_{2}$ flux values between 1.64 and $20.21 \mathrm{~m}^{-2} \mathrm{~h}^{-1}$ would be obtained. These values are certainly minima, as the effusive component, which is definitely present and which accounts for $\mathrm{CO}_{2}$ concentrations of $87 \%$ at a depth of $80 \mathrm{~cm}$, was not taken into consideration. As the flux values reported by Baubron et al. ${ }^{1}$ are an order of magnitude lower than the minima previously calculated, the reliability of their method is called into question.

Finally, we do not believe the deep source of the beach fumaroles can be distinguished from that of the crater fumaroles on the basis of the $\mathrm{CO}_{2} / \mathrm{He}$ ratio alone. Our data indicate that this ratio ranges between $1 \times 10^{5}$ and $5 \times 10^{5}$ in the crater area ${ }^{4,8,10}$. The $\mathrm{CO}_{2} /$ $\mathrm{He}$ ratio values of the beach fumaroles $\left(1 \times 10^{5}-3 \times 10^{5}\right)($ refs 1,2$)$ fall in the same range. In addition, the ${ }^{3} \mathrm{He} /{ }^{4} \mathrm{He}$ isotope ratios of both beach and crater fumaroles have similar values ${ }^{11}$ and show synchronous time variations.

B. Badalamenti S. GURRIERI Istituto di Geochimica dei Fluidi CNR,

P.M. NuCCIO

M. VELENZA

Istituto di Mineralogia Petrografia e

Geochimica,

Via Archirafi,

36 Palermo, Italy

BAUBRon ET AL. REPLY - Our main demonstration - that substantial gas release occurs diffusively from the slopes of the Fossa cone, in addition to fumarolic discharge - is supported by the results of Badalamenti et al. Our 1988 survey (soil, well, fumarole gases) was made not only on the cone but also on more than 150 sites on the main geological structures within the caldera (2.6 $\mathrm{km}^{2}$ ). Our flux estimate (30 tons $\mathrm{CO}_{2}$ per day) was strictly for soil degassing from the cone, excluding the fumerolic fields ${ }^{1}$. However, a computation error caused an erroneous estimate, subsequently corrected ${ }^{12}$, resulting in a value of 50 tons $\mathrm{CO}_{2}$ per day.

Flux measurements are made with a static (gas accumulation) method ${ }^{12}$, which gives a mean daily flow (see Fig. 2), and guarantees certain conditions such as no disturbance of soil permeability, a representative area $(0.5$ or $\left.1 \mathrm{~m}^{2}\right)$, integrated measurements $(6-24 \mathrm{~h})$ and good accuracy $( \pm 5 \%)$. To our knowledge, this method differs from that used by Badalamenti et al. $^{5}$, who measured flux through $1 \mathrm{~cm}^{2}$, but we have been unable to refer to the SIMP special volume. We would appreciate the chance to compare our methods.

\title{
Fetal clues to handedness
}

SIR - The interesting ultrasound findings of Hepper, Shahidullah and White, reported in Scientific Correspondence (Nature 347, $431 ; 1990)$, indicate that almost $95 \%$ of fetuses in utero show a bias towards sucking the thumb of the right hand. But whether this observation "supports genetic explanations of handedness" remains an open question.

The authors speculate that advanced right-sided neuromuscular development might be a trigger. This idea is presumably an extrapolation from the hypothesis that the advanced development of upper limbs compared with lower limbs in human embryos may be due to the development-promoting effects of the higher oxygen tension of the blood going to the upper limbs. Using the same reasoning, one can propose that as the right upper limb generally receives blood through a vessel that arises more proximally from the aorta than the supply to the left upper limb, development of the right might be sufficiently advanced over that of the left to promote early preference of the right thumb.

In 1989 and 1990, we carried out two more one-month programmes ${ }^{13,14}$, confirming a steady distribution and high level of soil gas anomalies. $\mathrm{CO}_{2}$ fluxes were comparable in 1988 and 1990 and lower by a factor of 2 in 1989 , that is 115 tons per day for the caldera floor in 1990 . Our results show that intermittent but intensive field campaigns can provide reliable data sets on degassing processes and budgets, although we agree with Badalamenti et al. that long-term monitoring requires continuous gas survey. We monitored $\mathrm{CO}_{2}, \mathrm{He}$ and $\mathrm{Rn}$ in a water well at the base of the cone continuously for six months in 1988 and 1989, during which we recorded variations synchronous with those at the crater ${ }^{15}$. This supports our claim ${ }^{1}$ that

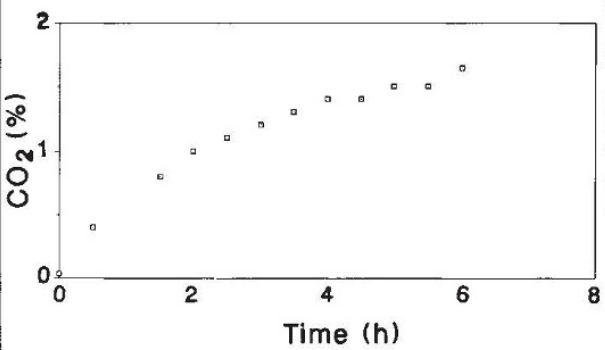

FIG. 2 Example of $\mathrm{CO}_{2}$ flux measurement (static method) from the foot of the cone. Flux is computed from the temporal increase of the $\mathrm{CO}_{2}$ concentration in a box. $\mathrm{C}$, gas concentration in the box; $\mathrm{Ce}$, limit gas concentration in the box (concentration of the gas entering into the box); $\mathrm{Ca}$, atmospheric concentration of the gas; Qe, exhaust flow of gas (equivalent to the input); T, time. The experimental data fit the theoretical curve $\left(\mathrm{C}=\mathrm{Ce}+(\mathrm{Ca}-\mathrm{Ce}) \mathrm{e}^{-\mathrm{Q} \mathrm{e}^{\top} \mathrm{N}}\right)$. The specific flow measurements are extrapolated to the whole surface using soil atmosphere concentrations and the direct relationship $=0.5+0.07$ $\left(\mathrm{CO}_{2} \%\right)$, which has remained steady over the past 3 years.
If the resolution of ultrasound imaging is adequate, it would be interesting to compare the dimensions of fetal right and left upper limbs in utero to see if there is a detectable difference in size that might correspond with this trophic hypothesis and its implications for handedness. This procedure might also throw some light on why a few fetuses show a preference for the left thumb. With luck, an occasional example of situs inversus (reversal of the normal pattern of asymmetries) might be encountered and provide an interesting test of the hypothesis, which would now predict a left-bias.

But all this sounds more like an epigenetic, rather than a genetic, explanation of handedness; it becomes a consequence of earlier asymmetries. A genetic explanation of handedness, if indeed one is required, may have to be sought at much earlier stages when asymmetries first arise in the embryonic disk.

30 Oakland Drive, Dawlish,

Richard DRyden

Devon EX7 9RN, UK

such distal gas leaks are suitable for geochemical monitoring.

Finally, our data and many others attest persistent and steady $\mathrm{He}$ depletion in the beach compared to crater fumaroles. This alone is not sufficient to infer a distinct origin for the fluids, but it does set important constraints on possible genetic models.

BRGM, Service Géologique

J. C. BAubron

National/GCH,

F-45060 Orléans Cedex 2, France

P. AlLARD

CFR, CNRS-CEA, CENS,

F-91191 Gif sur Yvette Cedex,

France

J.-P. Toutain

Observatoire Volcanologique du Piton de

la Fournaise,

F-97418 Plaine des Cafres, France

1. Baubron, J.-C., Allard, P. \& Toutain, J.-P., Nature 344 , $51-53(1990)$.

2. Carapezza, M., Nucclo, P. M. \& Valenza, M. Bull. Volcan. 44, 547-563 (1981).

3. Gurrieri, S. \& Valenza, M. SIMP Carapezza Spes, Vol. 1151-1158 (1988)

4. Rapporto GNV al Minstero per la Protezione Civile sull' intervento, strordinario a Vulcano (estate 1988).

5. Badalamenti, B., Falsaperia, S., Neri, G., Nuccio, P. M. \& Valenza, M. Boll. GNV 37-47 (1986).

6. Badalamenti, B., Gurrieri, S., Hauser, S., Parello, F. \& Valenza, M. SIMP Carapezza Spec. Vol. 893-899 (1988).

7. Badalamenti, B., et al. Boll. GNV 519-530 (1986).

8. Badalamenti, B., Gurrieri, S., Hauser, S., Tunani, F. \& Valenza, M. SIMP 39(2) 367-378 (1984).

9. Bertrami, R., Antrodicchia, R. \& Luzi, C. SIMP 43 153-161 (1984).

10. Cannata, S., Hauser, S., Parello, F. \& Valenza, M. Soc. Ital. Miner. Petrol. 43, 153-161 (1988).

11. Sano, Y., Wakita, H., Italiano, F. \& Nuccio, P. M. Geophys. Lett. 16, 511-514 (1989).

12. Tonani, F. Gruppo Nationale per le Vulcanologie. GNV-CNR meetings (Roma 1990).

13. Baubron, J.-C., BRGM Rep. R30110 (1989).

14. Baubron, J.-C., Miele, G. BRGM Rep. (in the press).

15. Toutain, J.-P. et. al. Bull. Volcan. (in the press).

16. Baubron, J.-C. et al. Bull. Geol. Soc. London (in the press). 